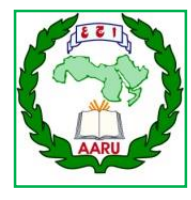

Arab Univ. J. Agric. Sci., Ain Shams Univ., Cairo, Egypt 29(2), 595-609, 2021

Website: http://ajs.journals.ekb.eg

DOI: 10.21608/ajs.2021.81294.1393

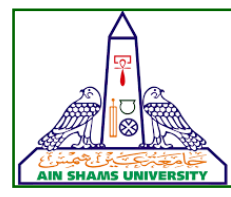

595

\title{
Biomass Production of Microalgae using Agricultural and Industrial Wastewater
}

\section{Merihan G Abdel-Raouf ${ }^{1 *}$, Sohair A Nasr², Elham M Aref ${ }^{1}$, Khadiga A Abou-Taleb ${ }^{2}$}

1- Agricultural Microbiology Research Dept, Soil, Water and Environment Research Institute, Agric Res Center, Giza, Egypt.

2- Agricultural Microbiology Dept, Faculty of Agriculture, Ain Shams University, P.O. Box 68, Hadayek Shubra, 11241 Cairo, Egypt

* Corresponding author: merihangamal100@ gmail.com

Received 18 June, 2021

Accepted 7 August, 2021

\begin{abstract}
Growing wastewater microalgae contributes to the elimination of nutrients present in wastewater because they need $\mathrm{N}$ and $\mathrm{P}$ for the synthesis of proteins, nucleic acid, and phospholipids. The most sustainable approach for achieving high biomass and high lipid buildup, along with environmental protection. In the current research, nine microalgae were cultivated on two variations of wastewater (agricultural and industrial dyes) and compared to the synthetic medium. The results indicated that after three weeks of the incubation period, the ability of microalgae to grow in sterilized (synthetic medium and wastewater) and gave greater biomass and chlorophyll $(a)$ than in non-sterilized ones. Out of the tested nine microalgae, four microalgae (Anabaena oryzae, Spirulina platensis, Anabaena sp (2) and Nostoc $\mathrm{sp}$ ) were selected which gave the highest significant values of dry weight, biomass productivity and chlorophyll (a) content. The selected microalgae showed the highest significant values of the chemical composition, i.e., total carbohydrate, protein and lipid when cultivated in agricultural wastewater more than those cultivated in both industrial dye's wastewater and synthetic broth medium. Among four microalgae, two microalgae of $A$.
\end{abstract}

oryzae HSSASE6 (KT277789), and S. platensis NIES-39 (A00800) were chosen where the chemical composition contents ranged from 1.17 to 1.21 -fold and 1.03 to 1.06 -fold of carbohydrate, 1.06 to 1.09 -fold and 1.88 to 1.93 fold of protein and 1.41 to 1.52 -fold and 1.76 to 1.90 -fold of lipid more than those of other microalgae, respectively. The agriculture wastewater was inoculated with a single culture of A. oryzae HSSASE6 (KT277789) or $S$. platensis NIES-39 (A00800) individually with $10 \%$ of inoculum size, which more preferred than was inoculated with consortia culture. Results also showed that A. oryzae HSSASE6 (KT277789) was more efficient strain for giving biomass and productivity in agricultural wastewater than $S$. platensis NIES-39 (A00800) (about 28\% more).

Keywords: Biomass production, Microalgae, Cyanobacteria, Green algae, Agricultural wastewater, Industrial dyes wastewater

\section{Introduction}

Microalgae, including eukaryotic and cyanobacterial algae, have shown an environmentally-friendly and renewable alternative to power-intensive and conventionally used biological processes (Singh et al 2015). 
Photosynthesis of microalgae and growth rates are significantly greater than most land plants (Li et al 2011). The microalgae photosynthesis was believed to have caused more than half of earth's oxygen (Tabatabaei et al 2011). Microalgae have been a major feedstock in recent years, but it is still unworkable in economic terms due to the high cost of algae cultivation (Guo et al 2013).

The use of microalgae for wastewater processing is not only an economic and sustainable tool for biofixing $\mathrm{CO}_{2}$, but also a sustainable source of organic biomass (Almomani et al 2019). The reason behind the use of mixotrophic microalgae for wastewater was their capacity in their development, with reduced levels of these substances in water, to use organic and inorganic carbon and inorganically Nitrogen and Phosphorus in wastewater (Sikder et al 2016). The main benefit of using microalgae in wastewater processing is the production of $\mathrm{O}_{2}$ through photosynthesis that is necessary to biodegrade carbonate materials for heterotrophic bacteria, in the treatment of aquaculture wastewater Chlorella minutissima microalgae could be used, and the method of cleaning reduces significantly the burden of compounds released to surface water,especially with the high quantity of nitrogen and phosphorus, salted water may be used for the processing and collection of stored lipids in their cells as a growth substrate (Hawrot et al 2020).

Commercial textile processes use large quantities of water and use hazardous materials. They contribute in environmental pollution by distributing untreated coloration effluents in the form of sludge in surrounding aquatic ecosystems. This lodge remains an end disposal problem and is critical in its ecotoxicological evaluation in order to minimize its effect on the ecosystem. The traditional waste processing methods do not fully color and detoxify the dye effluents except after therapy (Puvaneswari et al 2006).
The purpose of the present study was to assess the growth of microalgae on varied wastewater as a low-cost media for maximizing biomass production and their chemical composition.

\section{Materials and Methods}

\subsection{Sampling}

Two samples of wastewater were obtained from different regions in Egypt. Dyeswastewater sample was collected from Nabil textile factories, Shoubra El-Kheima, Qalubia government. Agriculture wastewater sample was obtained from (Zee El-krnin Dranige, Menoufi) government.

\subsection{Microalgae used}

Seven pure isolates, 5 isolates belonged to cyanobacterianamed: Nostoc sp, Anabaena sp (1), Anabaena sp (2), Wollea sp and Phormidium sp. and 2 isolates belonged to green algae named: Chlorella sp and Dunaliella sp in addition to two strains of cyanobacteria named: Anabaena oryzae HSSASE6 (KT277789) and Spirulina platensis NIES-39 (A00800) were used as a biomass production throughout this investigation, all used microalgae were kindly supplied by Agricultural Microbiology Research Department, Soil, Water and Environment Research Institute, ARC, Giza, Egypt.

\subsection{Media used}

The nutritive broth medium BG11 (Allen and Stanier 1968) was used to propagate of all used microalgae except of Spirulina platensis, Chlorella sp, and Dunealiella sp.

The nutritive agar medium BG11 was the same as nutritive BG11 adding agar $15 \mathrm{~g} / \mathrm{L}$.

Zarrouk medium (Zarrouk 1966) was used for propagation of Spirulina platensis strain. Bold's Basal medium (BBM) (Nichols and Bold 1965) was used for cultivation of Chlorella vulgaris green algae. 
Johnson's medium (Johnson et al 1968) it was used to grow culture Dunellila sp.

\subsection{Maintenance of microalgal cultures}

\subsubsection{Stock agar slants}

For each proper maintenance of the algal cultures. The agar slants were inoculated then incubated at $\left(28 \pm 2^{\circ} \mathrm{C}\right)$ under continuous fluorescent light of 3000 lux intensity to grow for two weeks thereafter, they were kept in a refrigerator. Subcultures were made regularly, nearly every month. These slant cultures were used as inoculum to liquid culture.

\subsubsection{Liquid culture}

One liter of the medium was poured in twoliter Erlenmeyer flasks. The culture flasks were plugged with cotton and sterilized in autoclave at $121^{\circ} \mathrm{C}$ for $20 \mathrm{~min}$. After cooling, the sterilized medium wasinoculated with $(50 \mathrm{mg})$ of the pre-culture organisms and incubated at $\left(28 \pm 2^{\circ} \mathrm{C}\right)$ under continuous fluorescent light of 3000 lux intensity. The culture flasks were aerated with air mixture to accelerate the algal growth.

\subsection{Cultivation of microalgae on wastewater samples}

To test the used algae for their efficacy in algal biomass, $10 \mathrm{ml}$ of 14 days old inoculum of each microalga were used to inoculate 500 $\mathrm{ml}$ flasks containing $200 \mathrm{ml}$ of sterilized wastewater samples and incubated at $\left(28 \pm 2^{\circ} \mathrm{C}\right)$ under continuous fluorescent light of 3000 lux intensity for 28 days, every seven days cell dry weight and chlorophyll $(a)$ content were estimated, and the intracellular contents were extracted from cells the selected algae and determined as described below.

\subsection{Chlorophyll (a) content determination}

The photosynthetic pigments chlorophyll (a) was extraction according to the method recommended by Henriques et al (2007): $2 \mathrm{~mL}$ of algae was transferred to eppendorf and centrifuged at $6000 \mathrm{rpm}$ in 10 minutes, washed the algae twice by distilled water and extracted by $2 \mathrm{~mL}$ acetone $80 \%$. Then, the extraction of chlorophyll was measured by spectrophotometer (at wave length $663 \mathrm{~nm}, 646 \mathrm{~nm}$ ). The calculation of chlorophyll was calculated based on Lichtenthaler and Wellburn (1983).

Chlorophyll $(a)=12.21 \mathrm{~A}^{663}-2.81 \mathrm{~A}^{646}$

Where, $\mathrm{A}^{663}=$ Absorbance at $663 \mathrm{~nm}$ and $\mathrm{A}^{646}=$ Absorbance at 646nm.

\subsection{Cell dry weight determination}

Samples of $200 \mathrm{ml}$ algal suspension were harvested, and then centrifuged at $3000 \mathrm{rmm}$ for $10 \mathrm{~min}$. The cells after being precipitated were washed twice with distilled water and dried overnight in an oven at $105^{\circ} \mathrm{C}$ for constant weight. Samples were cooled in desiccators for $30 \mathrm{~min}$ before dry weight measured (Leganes et al 1987).

\subsection{Intracellular contents extraction and as- say}

Lipids, carbohydrates and proteins contents were extracted from algal cells according to the method of (Kochert 1978). Representative samples from the cultures were collected and centrifuged to yield a packed cell pellet. The supernatant was discarded. The tubes containing the cell pellets were placed in ice and 10 $\mathrm{ml}$ of ice- cold $0.2 \mathrm{~N} \mathrm{HCIO}_{4}$ were added to each tube. The cell pellets were suspended thoroughly by vortexing or inversion. After 15 min at $4{ }^{\circ} \mathrm{C}$, the samples were centrifuged in an undercooling centrifuge and the supernatant was removed carefully. Extraction was repeated with further addition of $10 \mathrm{ml} 0.2 \mathrm{~N}$ $\mathrm{HCIO}_{4}$. The pellets contained the macromolecular-weight components (lipids, carbohydrates and proteins).

\subsubsection{Lipid content extraction}

Ten $\mathrm{ml}$ of chloroform-methanol solution $(2: 1 \mathrm{v} / \mathrm{v})$ were added to the pellets from the $\mathrm{HCIO}_{4}$ extraction. The pellets were suspended and allowed the suspension to stand for 5 
minutes at room temperature, after centrifugation, the supernatant was taken for determination of total lipids contents after addition of distilled water.

\subsubsection{Proteins and carbohydrates extraction}

One ml of $1 \mathrm{NNaOH}$ was added to the acidextracted lipid- free pellets. Samples were heated for 10 minutes in a boiling water bath to dissolve the pellets. Assay aliquots of the sample was carried out for protein and carbohydrates estimation.

\subsubsection{The total lipid, carbohydrates and pro- teins content determination}

The lipid content was determined according to (A.O.A.C 1965) as follows, after the extraction, the extract was transferred to accurately weighed receiving flasks and the solvent was distilled off and the last traces of solvent and moisture were removed by heating the flask in a hot air oven at $70^{\circ} \mathrm{C}$. The flasks were allowed to cool and then reweighed, and the lipid content was calculated.

The carbohydrate content was determined as glucose by the phenol sulphuric acid method (Dubois et al 1956). One $\mathrm{ml}$ of the sugar solution was mixed with $1 \mathrm{ml}$ of $5 \%$ redistilled phenol solution and then $5 \mathrm{ml}$ of sulphuric acid (AR). After cooling by standing for 10 minutes at room temperature, each tube was shaken and placed in a water bath at $30^{\circ} \mathrm{C} \pm 2$ for 20 minutes. The produced yellow orange color was determined calorimetrically at $490 \mathrm{~nm}$. A standard curve was constructed in the same way using different concentration of glucose $(10-100 \mu \mathrm{g} / \mathrm{ml})$.

The Total soluble proteins were quantitatively determined using the method described by Lowry et al (1951).

\subsection{Statistical analysis}

Data were statistically analyzed using IBM ${ }^{\circledR}$ SPSS ${ }^{\circledR}$ Statistics Version 14.0 according to Duncan's, (1955) at 5\% level. All the analyses were conducted in a triplicate.

\section{Results and Discussion}

\subsection{Cultivation and pre-selection of micro- algae in wastewater as growth medium}

The Chemical composition of wastewaters have been showing in Table 1.

Table 1. Chemical composition of wastewater:

\begin{tabular}{|c|c|c|}
\hline \multirow{2}{*}{ Element } & \multicolumn{2}{|c|}{ Concentration (mg/l) } \\
\cline { 2 - 3 } & $\begin{array}{c}\text { Agriculture } \\
\text { Wastewater }\end{array}$ & $\begin{array}{c}\text { Dyes } \\
\text { Wastewater }\end{array}$ \\
\hline NH $_{4}$ & 2.8 & N.D \\
\hline NO $_{3}$ & 0.07 & N.D \\
\hline $\mathbf{B}$ & 0.01 & N.D \\
\hline $\mathbf{C u}$ & ${ }^{*}<1.5$ & N.D \\
\hline $\mathbf{F e}$ & 0.121 & N.D \\
\hline $\mathbf{M n}$ & 0.069 & N.D \\
\hline $\mathbf{P}$ & ${ }^{*}<1.5$ & N.D \\
\hline $\mathbf{Z n}$ & 0.039 & N.D \\
\hline $\mathbf{C o}$ & ${ }^{*}<0.2$ & ${ }^{*}<0.2$ \\
\hline $\mathbf{C d}$ & ${ }^{*}<0.1$ & ${ }^{*}<0.01$ \\
\hline $\mathbf{P b}$ & 0.68 & ${ }^{*}<1.5$ \\
\hline $\mathbf{N i}$ & ${ }^{*}<0.3$ & ${ }^{*}<0.3$ \\
\hline $\mathbf{p H}$ & 8 & 9 \\
\hline $\mathbf{E c}$ & 2 & 1.7 \\
\hline $\mathbf{m s} / \mathbf{c m})$ & & \\
\hline $\mathrm{Detectio}$ & & \\
\hline
\end{tabular}

* Detection Limit $(\mu \mathrm{g} / \mathrm{L})$

N.D $=$ Not detected

In this experiment, Seven isolates, 5 isolates belonged to cyanobacteria named: Nostoc sp, Anabaena sp (1), Anabaena sp (2), Wollea sp and Phormidium sp and (2) isolates belonged to green algae named: Chlorella sp and Dunaliella sp in addition to two strains of cyanobacteria named: Anabaena oryzae HSSASE6 (KT277789) and Spirulina platensis NIES-39 (A00800) were cultivated at sterilized or non- sterilized form in two types of wastewater (agriculture and industrial dyes) as growth media and compared with synthetic medium for four weeks. 
Data pointed that the biomass and chlorophyll (a) content frommicroalgae tested in different media were increased gradually during the incubation periods and reached to maximum significant after three weeks then they were decreased in the $4^{\text {th }}$ week (Figs 1-3).

\subsubsection{In the nutritive broth medium (syn- thetic medium)}

Data in (Fig 1) revealed that the highest amount of biomass (cell dry weight) was achieved by Anabaena oryzae HSSASE (KT277789) in sterilized and non-sterilized media being 0.782 and $0.729 \mathrm{~g} / \mathrm{L}$, respectively, followed by Spirulina platensis NIES-39(A00800), Nostoc sp and Anabaena sp (2) in sterilized medium $(0.775,0.736$ and $0.708 \mathrm{~g} / \mathrm{L}$, respectively) and non-sterilized medium (0.720, 0.686 and $0.673 \mathrm{~g} / \mathrm{L}$, respectively).

Whereas the highest chlorophyll $(a)$ content recoded by two strains of Anabaena oryzae, Spirulina platensis and two isolate Nostoc sp and Anabaena sp (2) in sterilized and nonsterilized media which ranged from 7.42 to $8.43 \mathrm{mg} / \mathrm{L}$, and 7.11 to $7.56 \mathrm{mg} / \mathrm{L}$, respectively.

The lowest biomass $(0.263$ and $0.214 \mathrm{~g} / \mathrm{L})$ and chlorophyll (a) (2.74 and $2.26 \mathrm{mg} / \mathrm{L})$ contents were recorded by Dunelilla sp isolate in synthetic sterilized and non-sterilized media, respectively.

From the previous data, it was observed that the cultivation microalgae isolates and strains in sterilized synthetic medium on the 3 rd week was increased about ranged from 1.02 to 1.16 -fold compared to non-sterilized synthetic medium.

\subsubsection{In agricultural wastewater as a me- dium}

Data represented in (Fig 2) clearly showed that all tested microalgae appeared the well ability to grow in agricultural wastewater either in its sterilized form or non-sterilized form. The microalgae growth and chlorophyll (a) synthesis in agricultural wastewater sterilized form were higher than in non-sterilized form, it might be due that the sterilization process led to eliminate other organisms which caused decreased the tested algae growth (Abdel-Raouf et al 2012).

Data also show that after three weeks of incubation period, thehighest significant cell dry weight achieved by Anabaena oryzae, Spirulina platensis, Nostoc sp and Anabaena sp (2) were $0.772,0.764,0.721$ and $0.670 \mathrm{~g} / \mathrm{L}$ in sterilized form and $0.664,0.657,0.629$ and 0.607 $\mathrm{g} / \mathrm{L}$ in non-sterilized form, respectively. The lowest value of cell dry weight $(0.286$ and $0.221 \mathrm{~g} / \mathrm{L}$ ) was recorded by Dunelilla sp isolate in both sterilized and non-sterilized agricultural wastewater.

Moreover, the highest significant chlorophyll (a) synthesis was registered by Anabaena oryzae, Spirulina platensis, Nostoc sp and Anabaena sp 2 being 8.52, 8.44, 8.36 and $7.22 \mathrm{mg} / \mathrm{L}$ in sterilized form while being 7.14 , $6.98,6.66$ and $6.42 \mathrm{mg} / \mathrm{L}$ in non-sterilized form of agricultural wastewater, respectively. The minimum value of chlorophyll $(a)$ was 3.63 and 2.54 synthesized by Dunelilla sp isolate, respectively.

Furthermore, it could be stated that the cultivation the tested microalgae in sterilized agricultural wastewater as a growth medium led to increase the biomass and chlorophyll $(a)$ content approximately ranged from 1.01 to 1.09 -fold and from 1.02 to 1.54 -fold as compared to non-sterilized form, respectively.

\subsubsection{In industrial dyes wastewater as a me- dium}

Industrial wastewater such as textile wastewater is a cheap source for water, which additionally contains necessary nutrients (phosphate, nitrates, micronutrients etc.) and organic dyes (potential carbon source) for algae cultivation (Fazal et al 2018).

Results in (Fig 3) indicated that the microalgae of Spirulina platensis appeared the best one significant for growth $(0.566 \mathrm{~g} / \mathrm{L})$ in nonsterilized industrial dyes wastewater and chlorophyll (a) $(6.02 \mathrm{mg} / \mathrm{L})$ after three weeks of incubation period. Whereas, in sterilized industrial dyes wastewater Spirulina platensis 

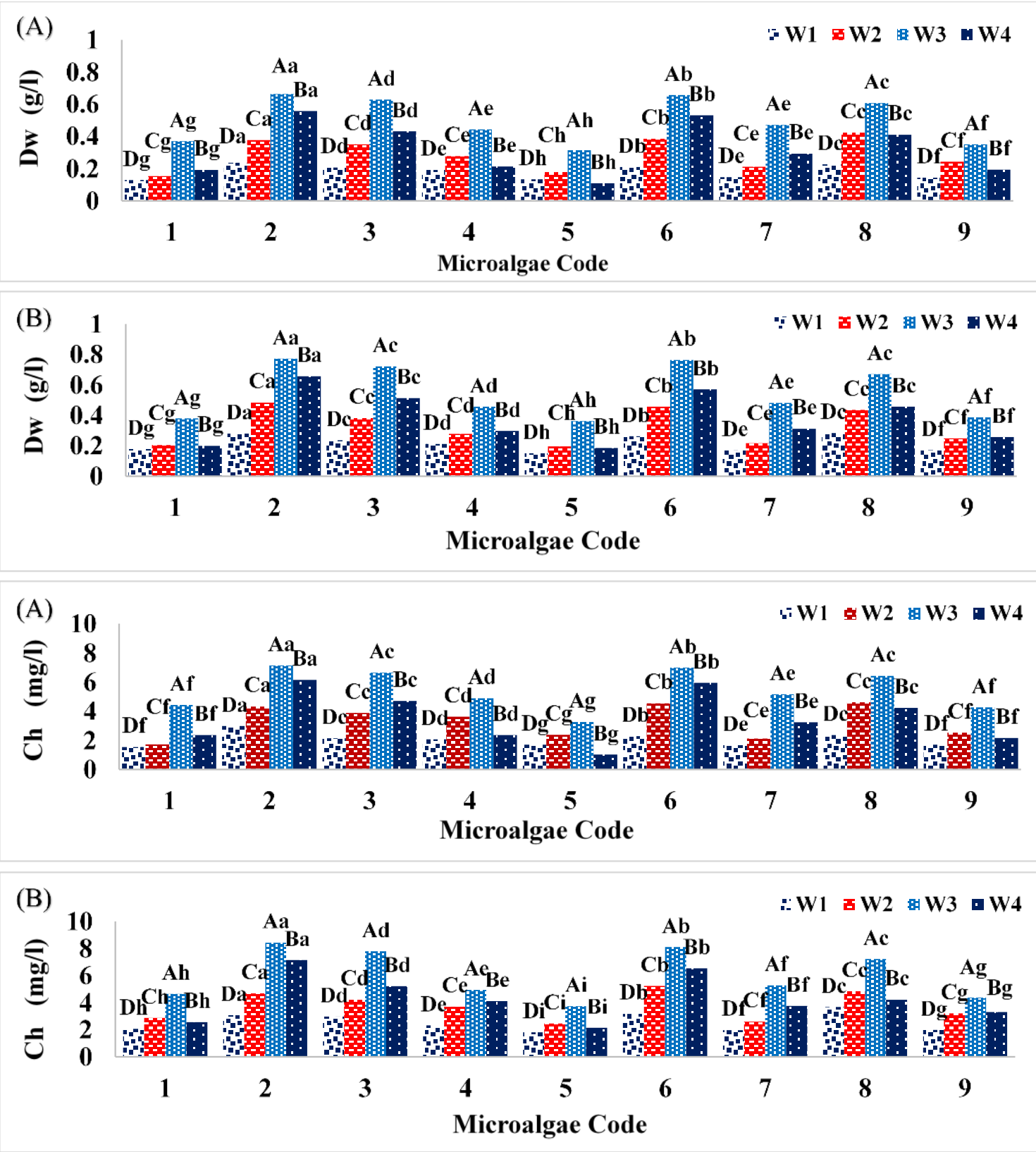

Fig. 1 Biomass, and chlorophyll (a) production during 4 weeks at $25^{\circ} \mathrm{C}$ on non-sterilized (A) and sterilized (B) synthetic media under static condition.

- $1=$ Chlorella $\mathrm{sp}, 2=$ Anabaena oryzae, $3=$ Nostoc $\mathrm{sp}, 4=$ Phormidium $\mathrm{sp}, 5=$ Dunelilla $\mathrm{sp}, 6=$ Spirulina platensis, 7=Anabaena $\mathrm{sp}(1), 8=$ Anabaena $\mathrm{sp}(2), 9=$ Wollae $\mathrm{sp}$

- A,B Values with capitalletters in the same row with different superscripts are significant difference (at $p \leq 0.05$ ) between the same microalgae grown during different weeks.

- $\quad$ a,b Values with small letters in the same column having different superscripts are significa nt difference (at $p \leq 0.05$ ) between different microalgae grown for the same week. 

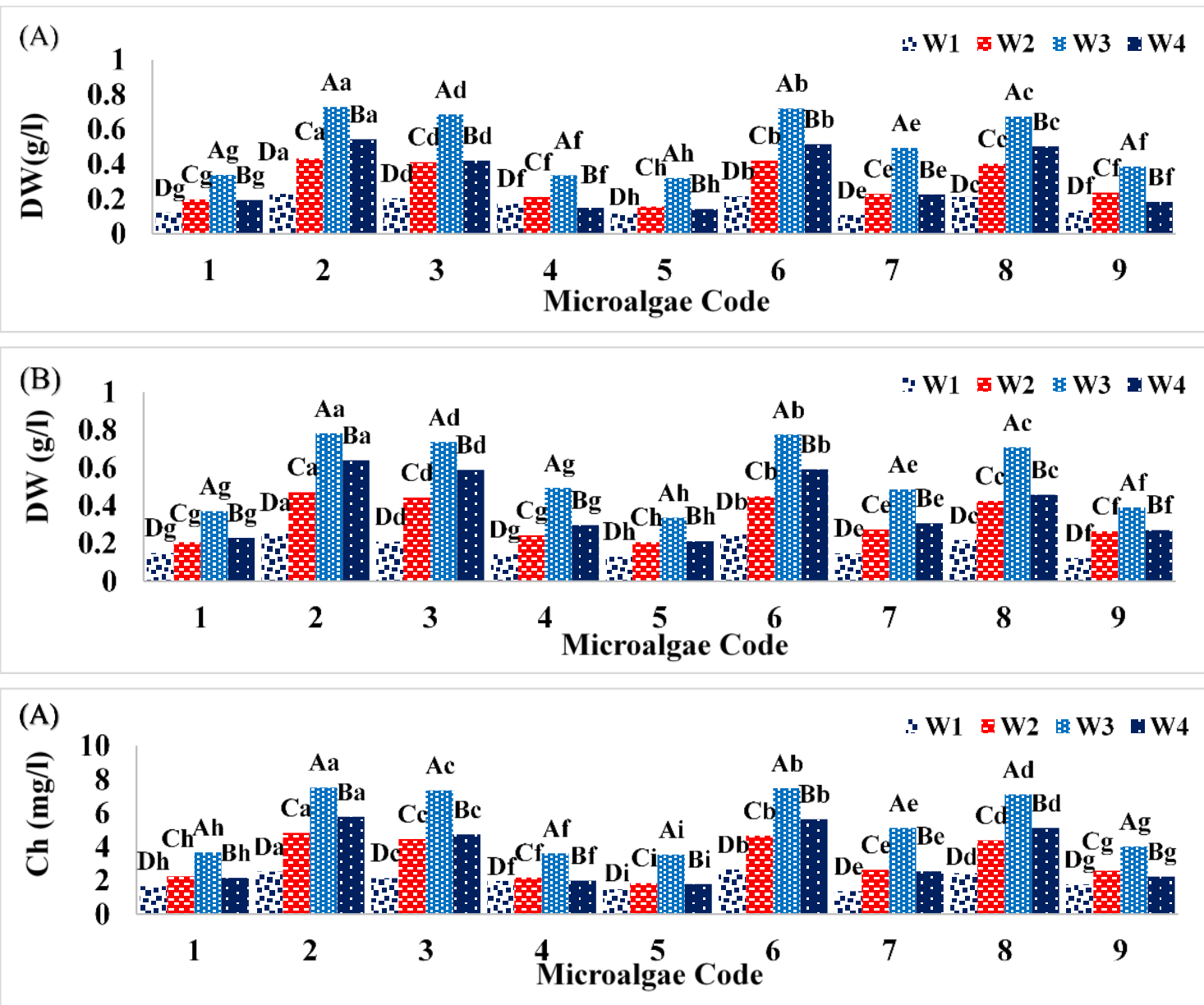

(B)

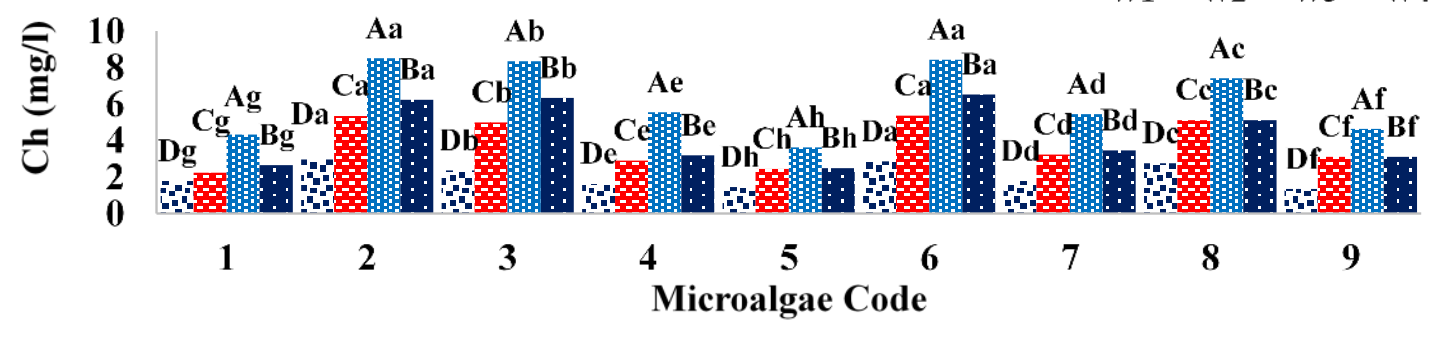

Fig. 2 Biomass, and chlorophyll (a) production during 4 weeks at $25{ }^{\circ} \mathrm{C}$ on non-sterilized (A) and sterilized (B) agricultural wastewater a a medium under static condition.

- 1=Chlorella $\mathrm{sp}, 2=$ Anabaena oryzae, 3= Nostoc sp,4=Phormidium sp,5=Dunelilla sp, $6=$ Spirulina platensis, $7=$ Anabaena $\mathrm{sp}(1), 8=$ Anabaena $\mathrm{sp}$ (2),9= Wollae $\mathrm{sp}$

- A, B Values with capitalletters in the same row with different superscripts are significant difference (at $p \leq 0.05$ ) between the same microalga e grown during different weeks.

- $\quad a, b$ Values with small letters in the same column having different superscripts a re significant difference (at $p \leq 0.05$ ) between different microalgae grown for the same week. 
Merihan, Sohair, Elham, Khadiga
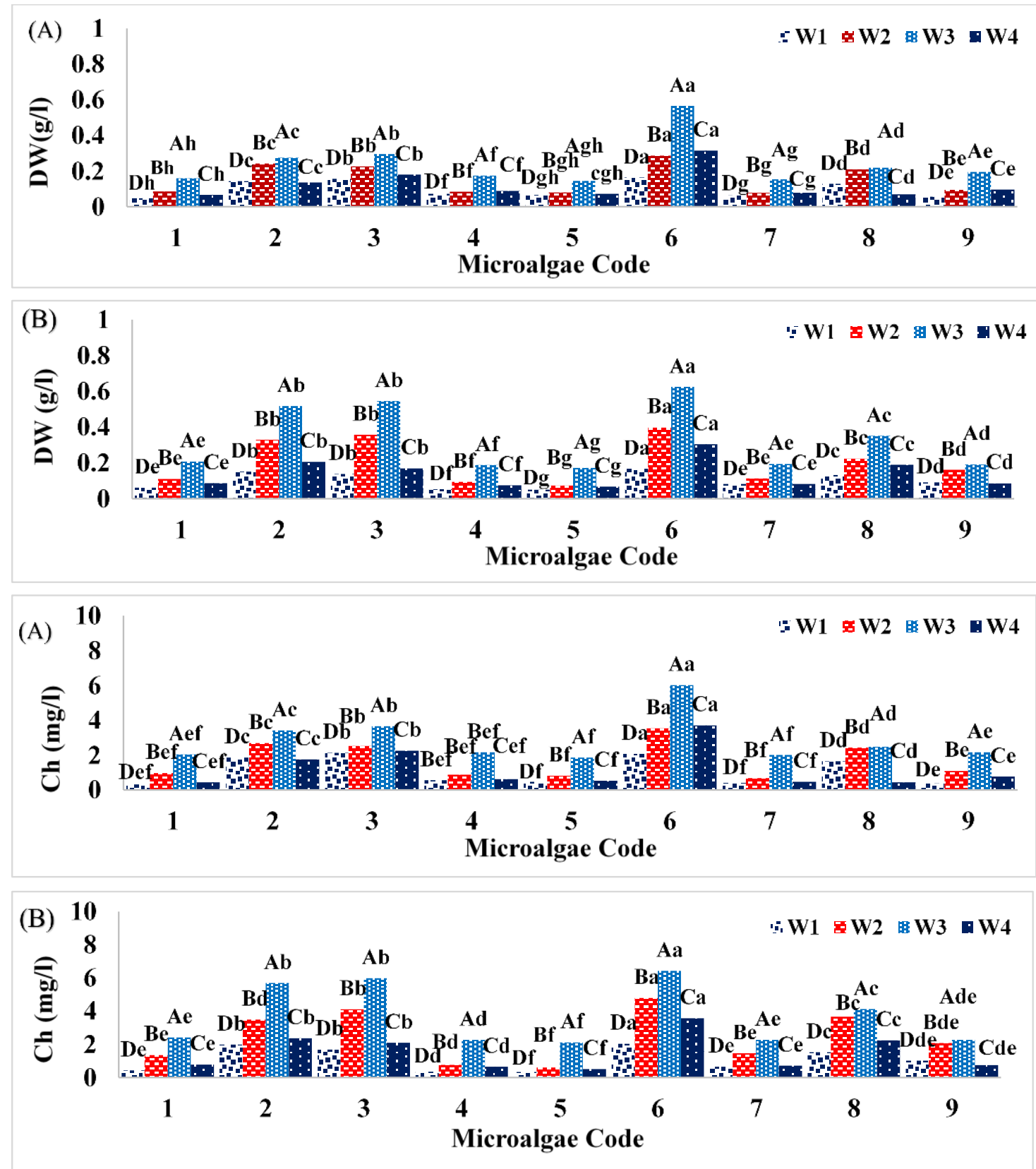

Fig. 3 Biomass, and chlorophyll (a) production during 4 weeks at $25^{\circ} \mathrm{C}$ on non-sterilized (A) and un (B) industrial dyes wastewater as a medium under static condition.

- $1=$ Chlorella $\mathrm{sp}, 2=$ Anabaena oryzae, $3=$ Nostoc $\mathrm{sp}, 4=$ Phormidium $\mathrm{sp}, 5=$ Dunelilla $\mathrm{sp}, 6=$ Spirulina platensis, $7=$ Anabaena $\mathrm{sp}(1), 8=$ Anabaena $\mathrm{sp}(2), 9=$ Wollae $\mathrm{sp}$

- A,B Values with capital letters in the same row with different superscripts are significant difference (at $p \leq 0.05$ ) between the same microalga e grown during different weeks.

- $\quad \mathrm{a}, \mathrm{b}$ Values with small letters in the same column having different superscripts a re significant difference (at $p \leq 0.05$ ) between different microalgae grown for the same week. 

and Industrial Wastewater

and Nostoc sp gave the highest significant dry weight $(0.625$ and $0.546 \mathrm{~g} / \mathrm{L})$ and chlorophyll (a) $(6.13$ and $5.98 \mathrm{mg} / \mathrm{L})$, followed by Anabaena oryzae and Anabaena sp 2 gave 0.518 and $0.352 \mathrm{~g} / \mathrm{L}$ of dry weight and 5.70 and 4.13 $\mathrm{mg} / \mathrm{L}$ of chlorophyll $(a)$ content after three weeks of incubation period, respectively.

The lowest amount of dry weight $(0.172$ and $0.145 \mathrm{~g} / \mathrm{L})$ and chlorophyll $(a)$ (2.12 and $1.86 \mathrm{mg} / \mathrm{L}$ ) were registered by Dunelilla $\mathrm{sp}$ isolate in both sterilized and non-sterilized industrial dyes wastewater after three weeks of incubation period .results are generally in line with Lim et al (2010) who studied the cultivation of C. vulgaris, from textile waste effluent, they stated that the dilution of the textile waste effluents is an important factor affecting the algal growth and biomass productivity. Moreover C. vulgaris grew in $100 \%$ waste effluent, although the final biomass attained was significantly lower $(\mathrm{p}<0.05)$ than that grown in 20 $80 \%$ textile waste concentration.
From the above results, it could be stated that the four microalgae of $A$. oryzae HSSASE (KT277789), S. platensis NIES-39 (A00800), Nostoc sp and Anabaena sp (2) were favoured than other tested algae which gave the highest significant values of dry weight and chlorophyll $(a)$ content after three weeks of incubation periods in synthetic medium and both agricultural wastewater and industrial dyes wastewater. So, these algae were selected for the determination of the biochemical composition.

The biomass productivity of four selected algae in synthetic medium and both agricultural and industrial dyes wastewater was calculated. Data represented in Table 2 showed that the highest productivity recorded in agricultural wastewater ranged from 0.236 to $0.260 \mathrm{~g} / \mathrm{L} /$ week. Whereas the lowest productivity recoded in industrial dyes wastewater ranged from 0.117 to $0.208 \mathrm{~g} / \mathrm{L} /$ week.

Table 2. The biomass and chlorophyll $(a)$ and productivity on sterilized different wastes media at room temperature under static condition

\begin{tabular}{|c|c|c|c|c|}
\hline $\begin{array}{c}\text { Sample of } \\
\text { wastewater }\end{array}$ & Microalgae code & $\begin{array}{c}\text { Biomass } \\
(\mathbf{g} / \mathbf{L})\end{array}$ & $\begin{array}{c}\text { Chlorophyll }(\boldsymbol{a}) \\
(\mathbf{m g} / \mathbf{L})\end{array}$ & $\begin{array}{c}\text { Productivity } \\
(\mathbf{g} / \mathbf{L} / \mathbf{w})\end{array}$ \\
\hline \multirow{4}{*}{ Agriculture } & Anabaena oryzae & $0.782^{\mathrm{Ab}}$ & $8.52^{\mathrm{Ab}}$ & $0.260^{\mathrm{Ab}}$ \\
\cline { 2 - 5 } & Nostoc sp & $0.736^{\mathrm{Ac}}$ & $8.36^{\mathrm{Ac}}$ & $0.245^{\mathrm{Ac}}$ \\
\cline { 2 - 5 } & Spirulina platensis & $0.775^{\mathrm{Aa}}$ & $8.44^{\mathrm{Aa}}$ & $0.258^{\mathrm{Aa}}$ \\
\cline { 2 - 5 } & Anabaena $\mathrm{sp}(2)$ & $0.708^{\mathrm{Ad}}$ & $7.42^{\mathrm{Ad}}$ & $0.236^{\mathrm{Ad}}$ \\
\hline \multirow{4}{*}{ Industrialdyes } & Anabaena oryzae & $0.518^{\mathrm{Cb}}$ & $5.70^{\mathrm{Cb}}$ & $0.173^{\mathrm{Cb}}$ \\
\cline { 2 - 5 } & Nostoc $\mathrm{sp}$ & $0.546^{\mathrm{Cc}}$ & $5.98^{\mathrm{Cc}}$ & $0.182^{\mathrm{Cc}}$ \\
\cline { 2 - 5 } & Spirulina platensis & $0.625^{\mathrm{Ca}}$ & $6.14^{\mathrm{Ca}}$ & $0.208^{\mathrm{Ca}}$ \\
\cline { 2 - 5 } & Anabaena $\mathrm{sp}(2)$ & $0.352^{\mathrm{Cd}}$ & $4.13^{\mathrm{Cd}}$ & $0.117^{\mathrm{Cd}}$ \\
\hline \multirow{2}{*}{$\begin{array}{c}\text { Synthetic media } \\
\text { as control }\end{array}$} & Anabaena oryzae & $0.772^{\mathrm{Bb}}$ & $8.43^{\mathrm{Bb}}$ & $0.257^{\mathrm{Bb}}$ \\
\cline { 2 - 5 } & Nostoc $\mathrm{sp}$ & $0.721^{\mathrm{Bc}}$ & $7.79^{\mathrm{Bc}}$ & $0.240^{\mathrm{Bc}}$ \\
\cline { 2 - 5 } & Spirulina platensis & $0.764^{\mathrm{Ba}}$ & $8.11^{\mathrm{Ba}}$ & $0.255^{\mathrm{Ba}}$ \\
\cline { 2 - 5 } & Anabaena $\mathrm{sp}(2)$ & $0.670^{\mathrm{Bd}}$ & $7.22^{\mathrm{Bd}}$ & $0.223^{\mathrm{Bd}}$ \\
\hline
\end{tabular}

- A,B Values with capitalletters in the same row with different superscripts are significant difference (at $p \leq 0.05$ ) between the same microalga grown during different weeks.

- $a, b$ Values with small letters in the same column having different superscripts are significant difference (at $p \leq 0.05$ ) between different microalga e grown for the same week. 
The selected algae gave the highest significant values of biomass, productivity and chlorophyll $(a)$ content in agricultural wastewater which increased approximately ranged from 1.01 to 1.11 -fold, 1.01 to 1.11 -fold, and 1.01 to 1.11 -fold more than in synthetic medium and ranged from 1.24 to 3.07 -fold, 1.24 to 3.34 -fold and 1.24 to 2.86 -fold over increased in industrial dyes wastewater, respectively.

These results are agreement with those of Tan et al (2015) which reported that microalgae were capable to survive in wastewater by utilizing the nutrients for growth. As well as microalgae cultivation by using wastewater could become the cheapest and most effective way to achieve maximum biomass production followed by high lipid excretion and environmental sustainability (Mata et al 2014). successful cultivation to microalgae on an industrial scale using wastewater and flue gases depend on the selection of excellent microalgal strains (Lage et al 2018).

\subsection{Intracellular contents accumulation}

The biochemical composition (carbohydrate, protein and lipid) of the selected microalgae were illustrated in (Fig 4A-C).

Results in (Fig 4A) indicated that A. oryzae accumulated the maximum significant amount of carbohydrates when grown in synthetic medium, agricultural wastewater and industrial dyes wastewater were 289.2, 311.0, and 269.4 $\mathrm{mg} / \mathrm{L}$, respectively followed by Anabaena sp (2) when grown in synthetic medium (228.8 $\mathrm{mg} / \mathrm{L}$ ) and by S.platensis when grown in both agricultural wastewater and dyes wastewater $(272.2,176.7 \mathrm{mg} / \mathrm{L})$, respectively.

Whereas the minimal amount of carbohydrate $(167.9,257.6$, and $145.0 \mathrm{mg} / \mathrm{L})$ was accumulated by Nostoc sp grown in synthetic medium, agricultural wastewater and industrial dyes wastewater, respectively.

Furthermore, results indicated that these microalgae were preferred to cultivate in agricultural wastewater and produced carbohydrates with increase over about $10-50 \%$ than cultivate in synthetic medium and about 20$90 \%$ than cultivate in industrial dyes wastewater.
Data illustrated by (Fig 4B) shows that $S$. platensis NIES-39 (A00800) and A. oryzae HSSASE (KT277789) had a high significant content of protein through grown in synthetic medium (326.6 and $194.0 \mathrm{mg} / \mathrm{L}$ ), agricultural wastewater (362.5 and $204.6 \mathrm{mg} / \mathrm{L}$ ) and industrial dyes wastewater (284.4 and $140.6 \mathrm{mg} / \mathrm{L}$ ), respectively. From these results it was observed that the protein content in both strains after cultivated in agricultural wastewater was increased about $10 \%$ as compared to cultivated in synthetic medium, but it was decreased about $13-28 \%$ after cultivated in industrial dyes wastewater as compared by control (synthetic medium).

The lowest protein content appeared in Nostoc sp aftercultivated in synthetic medium, agricultural wastewater, and industrial dyes wastewater was $125.0,187.5$, and $69.9 \mathrm{mg} / \mathrm{L}$, respectively.

Results in (Fig 4C) exhibited that a high significant content of lipid was accumulated in S. platensis followed by A. oryzae of 74.0 and $59.3 \mathrm{mg} / \mathrm{L}$ after cultivated in agricultural wastewater and 50.4 and $36.6 \mathrm{mg} / \mathrm{L}$ after cultivated in synthetic medium and 35.0 and 27.4 $\mathrm{mg} / \mathrm{l}$ after cultivated in industrial dyes wastewater, respectively. Whereas Nostoc sp accumulated low amount of lipid either synthetic medium and both wastewater of agriculture or industrial dyes used for growth being 27.2 and 39.0 or $16.3 \mathrm{mg} / \mathrm{L}$, respectively.

From the previous results, it was found that agricultural wastewater was preferred for using as growth medium of microalgae than for using synthetic medium and industrial dyes wastewater which it stimulated the growth algae (biomass) and increased the biochemical composition. In specific, (Falkowski and Raven 2007 and Borowitzka et al 2016) reported that the microalgae assimilate ammonia $\left(\mathrm{NH}_{3}\right)$ and phosphate $\left(\mathrm{PO}_{4}\right)$ directly and in concert for cell growth and metabolic function. Moreover, agricultural wastewater was rich with nutrients and dissolved nitrogen and phosphorus stimulating the growth and biochemical composition of microalgae have been stated by (Abdel-Raouf et al 2012) and industrial dyes wastewater 

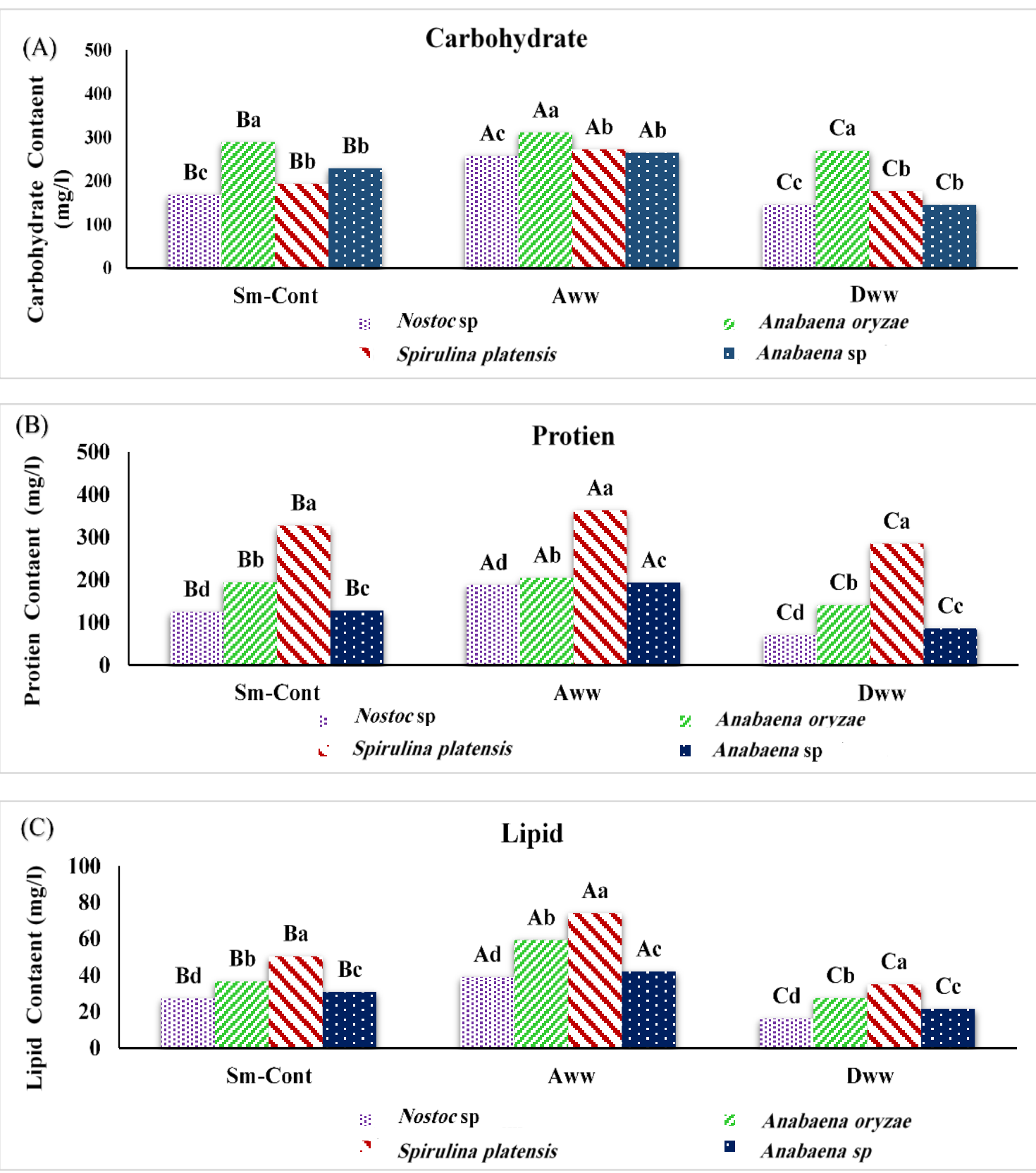

Fig. 4 The contents of carbohydrates(A), protein(B), lipid(C) of the most efficient microalgae grown on synthetic medium, agricultural wastewater and industrial dyes wastewater.

- Sm-Cont = Synthetic medium- as control, Aww = Agriculture wastewater, and Dww = Dye's wastewater.

- A, B Values with capital letters in the same row with different superscripts a re significant difference (at $p \leq 0.05$ ) between the same microalgae grown during different weeks.

- $\quad$ a,b Values with small letters in the same column having different superscripts are significant difference (at $p \leq 0.05$ ) between different microalgae grown for the same week. 
was rich in dissolved and suspended solids and heavy metals. These components including the dye itself can be implicated for the reduction in growth and biomass productivity and biochemical composition of the microalga have been reported by (Mathur et al 2012, Chia et al 2013 and Fazal et al 2018).

So, it could be mentioned that $S$. platensis and $A$. oryzae were the best used algae for biomass production and biochemical composition in agricultural wastewater and they were chosen for next study.

\subsection{Effect of single and consortia microalgae strains in biomass production}

Data in (Fig 5A) exhibited that A. oryzae HSSASE (KT277789) or S. platensis NIES-39 (A00800) dry weight and productivity were significantly $(p \leq 0.05)$ increased when inoculated these algae as a single culture in agricultural wastewater with inoculum size of $10 \%$ $(v / v)$ individually were 1.47 or $1.14 \mathrm{~g} / \mathrm{L}$ and 0.49 or $0.38 \mathrm{~g} / \mathrm{L} / \mathrm{w}$ with a high determination coefficient $\left(\mathrm{R}^{2}=1\right)$, respectively.

Whereas the cultivation of agricultural wastewater with mixed cultures of A. oryzae: S. platensis, the biomass and productivity were increased by increase the inoculum size and achieved maximal significant $(p \leq 0.05)$ when inoculated with inoculum sizes of 6: $4 \%(\mathrm{v} / \mathrm{v})$ which gave $0.89 \mathrm{~g} / \mathrm{L}$ of dry weight and 0.29 $\mathrm{g} / \mathrm{L} / \mathrm{w}$ of productivity, respectively. A low determination coefficient $\left(\mathrm{R}^{2}=0.4\right)$ between inoculum sizes of co-cultures and each of biomass and productivity.

From the above data, it could be observed that the biomass and productivity of $A$. oryzae or $S$. platensis in wastewater were increased when the tested microalgae inoculated as a monoculture at $10 \%$ of inoculum size which they more increased approximately $64 \%$ or $28 \%$ than inoculated with consortia at $6: 4 \%$ of inoculumsize. It might be due to the mixed microalgae were competitive in maintaining the microalgal community when compared with the single microalgae has been reported by $\mathrm{Qu}$ et al (2019). Moreover, Bohutskyi et al (2016) suggested that the monocultures of Chlorella and Scenedesmus showed higher growth rates and productivity than a mixed culture of five species. As well as Qu et al (2019) found that the monoculture had advantages over the mixed culture of microalgae in terms of nutrient removal and lipid production.

Data also indicated that $A$. oryzae was more favoured for cultivating in agricultural wastewater than S. platensis, whichitled to increase biomass and productivity about $28 \%$ over increase than S. platensis. 

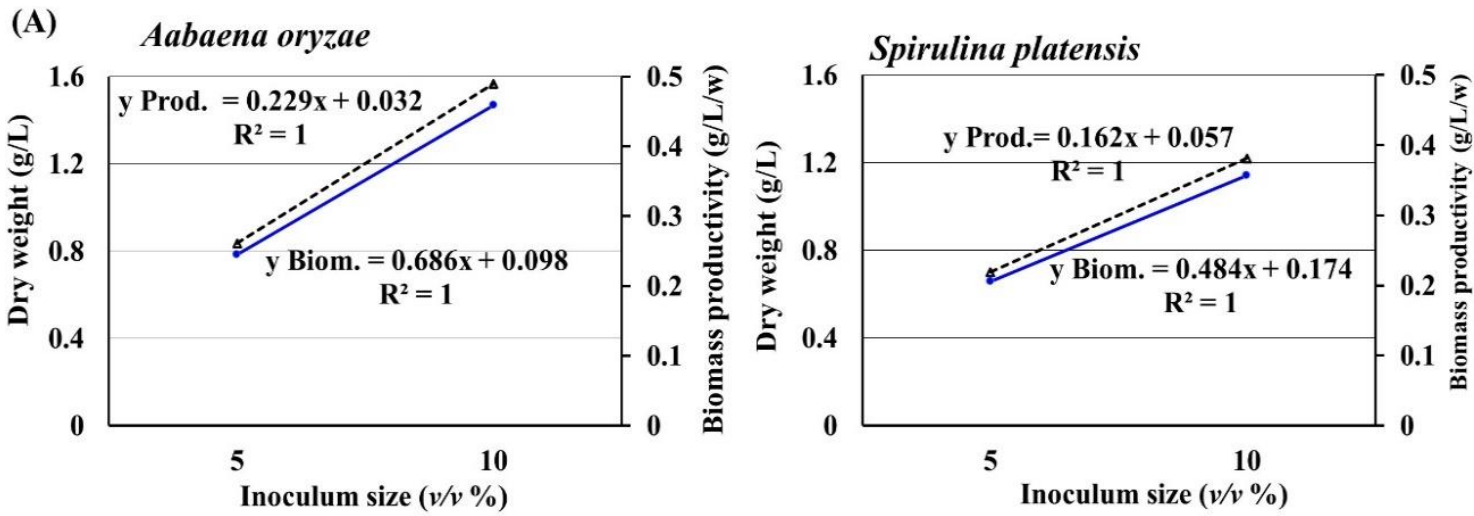

(B)

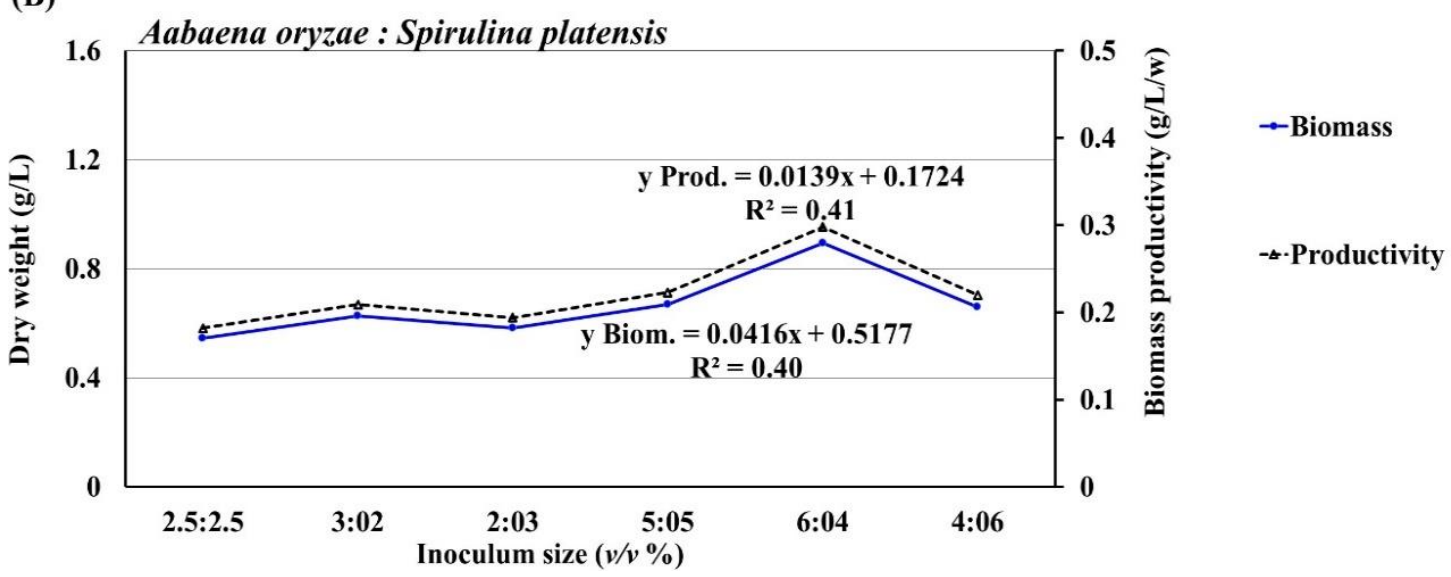

Fig. 5 Effect of single(A) and consortia(B) cultures of Anabaena oryzae HSSASE (KT277789) or Spirulina platensis NIES-39 (A00800) on Biomass production and productivity after cultivation in agricultural wastewater for three weeks at $25^{\circ} \mathrm{C}$.

\section{Conclusions}

This study indicated that nine microalgae (cyanobacteria and green algae) were capable of growing in agricultural and industrial dyes wastewater as cultivated media and produced more biomass than that grown in synthetic medium, resulting in low medium growth costs and a reduction in environmental pollution. One strain of Anabaena oryzae HSSASE6 (KT277789) was of nine microalgae, with higher dry weight, chlorophyll ( $a$ ) content, and productivity, Also rich in carbohydrates, protein, and lipid, during cultivation in agricultural wastewater than in the synthetic media and in the industrial dyes wastewater and the biomass increased when inoculated these algae as a single culture in agricultural wastewater with inoculum size of $10 \%(\mathrm{v} / \mathrm{v})$ individually .In order to grow this strain with and achieved highest biomass, agricultural wastewater was used as a low-cost medium.

\section{References}

Abdel-Raouf N, Al-Homaidan AA, Ibraheem IB (2012) Microalgae and wastewater treatment. Saudi J Biol Sc 19, 257-275.

Allen MM, Stanier RY (1968) Selective isolation of blue-green algae from water and soil. J Gen Microbiol 51, 203-209. 
Almomani F, Al Ketife A, Judd S, Shurair M, Bhosale RR, Znad H, Tawalbeh M (2019) Impact of $\mathrm{CO}_{2}$ concentration and ambient conditions on microalgal growth and nutrient removal from wastewater by a photobioreactor. Sci Total Environ 662, 662-671.

A.O.A.C. (1965) Official Methods of Analysis, $10^{\text {th }}$ ed, Association Official Agricultural Chemist, Washington, D.C.

Bohutskyi P, Kligerman DC, Byers N, Nasr LK Cua C, Chow S, Su C, Tang Y, Betenbaugh MJ, Bouwer EJ (2016) Effects of inoculum size, light intensity, and dose of anaerobic digestion centrate on growth and productivity of Chlorella, and Scenedesmus, microalgae and their polyculture in primary and secondary wastewater. Algal Res 19, 278-290

Borowitzka, MA, Beardall, J, Raven, J (2016) The Physiology of microalgae, Springer International Publishing, pp 143-155.

Chia MA, Lombardi AT, Melao MGG (2013) Growth and biochemical composition of Chlorella vulgaris in different growth media. Ann Braz Acad Sci 85, 1427-1438.

Dubois M, Gilles KA, Hamilton JK, Rebers PT, Smith F (1956) Colorimetric method for determination of sugars and related substances. Anal Chem 28, 350-356

Duncan DB (1955) Multiple range and multiple F test. Biometrics11, 1-42.

Falkowski, PG, Raven, JA (2007) Aquatic Photosynthesis, $2^{\text {nd }}$ ed, Princeton University Press, New Jersey, USA, pp 156-201.

Fazal T, Mushtaq A, Rehman, F, Khan, AU, Rashid, N, Farooq W, Rehman MSU, Xu J (2018) Bioremediation of textile wastewater and successive biodiesel production using microalgae. Renew Sustain Energy 82, 31073126.

Guo Z, Yuan L, Haiyan G, Song Y, Jun M (2013) Microalgae cultivation using an aquaculture wastewater as growth medium for biomass and biofuel production. J Environ Sci 25, S85-S88.
Hawrot-Paw M, Koniuszy A, Gałczynska M, Zajac G, Szyszlak-Bargłowicz J (2020) Production of microalgal biomass using aquaculture wastewater as growth medium. Water 12 , 106.

Henriques M, Silva A, Rocha J (2007). Extraction and quantification of pigments from a marine microalga: a simple and reproducible method. Communicating Current Research and Educational Topics and Trends in Applied Microbiology A.Mesndez-Vilas (Ed).

Johnson MK, Johnson J, Maceloroyr D, Speerh L, Bruffb S (1968) Effects of salts on the halophilic algae Dunaliella viridis. J Bacteriol 95, 1461-1468.

Kochert G (1978) Quantitation of the macromolecular components of microalgae. In: Hellebust, JA, Craigie, JS (Eds). Handbook of Phycological Methods: Physiological and Biochemical Methods. Cambridge University Press, London, pp 189-195

Lega s, Gojkovic Z, Funk C, Gentili FG(2018) Algal biomass from wastewater and flue gases as asource of bioenergy. Energies 11, 664,130 .

Leganes F, Sanchez-Maeso E, Fernandez-Valint E (1987) Effect of indol acetic acid on growth and dinitrgen fixation by blue green algae. Seven Bot Tidskr 64, 460- 461.

Li Y, Zhou W, Hu B, Min M, Chen P, Ruan $R R$ (2011) Integration of algae cultivation as biodiesel production feedstock with municipal wastewater treatment: strains screening and significance evaluation of environmental factors. Bioresour Technol 102, 10861-10867.

Lichtenthaler HK, Wellburn AR (1983). Determinations of total carotenoids and chlorophylls a and b of leaf extracts in different solvents. Biochem Soc T 11, 591-592

Lim SL, Chu WL, Phang SM (2010) Use of Chlorella vulgaris for bioremediation of textile wastewater. J Bioresource Technol 101, 7314-7322. 
Lowry OH, Rosebrough NJ, Farr AL, Randall RJ (1951) Protein Measurement with the Folin Phenol Reagent. J Biol Chem 193, 265-275.

Mata TM, Santosa J, Mendesa AM, Caetanoa NS, Martinsc AA (2014) Sustainability evaluation of biodiesel produced from microalgae Chlamydomonas sp. Grown in brewery wastewater. Chem Eng Trans 37, 823-828.

Mathur N, Bhatnagar P, Sharma P (2012) Review of the mutagenicity of textile dye products. Univers J Environ Res Technol 2, 118.

Nichols, HW, Bold, HC (1965) Trichosarcina polymorpha gen.et Sp. Nov. J Phycol 1, 34-38.

Puvaneswari N, Muthukrishnan J, Gunasekaran P(2006) Toxicity assessment and microbial degradation of azo dyes. Indian J Exp Biol 44, 618-626.

Qu Z, Duan P, Cao X, Liu M, Lin L, Li M (2019) Comparison of monoculture and mixed culture (Scenedesmus obliquus and wild algae) for $\mathrm{C}, \mathrm{N}$, and $\mathrm{P}$ removal and lipid production. Environ Sci Pollut Res 26, 20961-20968.
Sikder MNA, Min WW, Ziyad AO, Kumar PP, Kumar RD (2016) Sustainable treatment of aquaculture effluents in future-A review. Int Res $J$ Adv Eng Sci 1, 190-193.

Singh B, Bauddh K, Bux F (2015). Algae and environmental sustainability, New Delhi, Springer, New Delhi, India, pp 1-23.

Tabatabaei M, Tohidfar M, Jouzani GS, Safarnejad M, Pazouki M (2011) Biodiesel production from genetically engineered microalgae: future of bioenergy in Iran. Renew Sustain Energy Rev 15, 1918-1927.

Tan C, Chech W, Tau C, Show P, Juan J, Chang JS (2015) Algae Cultivation in Wastewater for Biodiesel - A Review. Chem Eng Trans 45, 1393-1398.

Zarrouk C (1966) Contribution to the study of a cyanophyta, the influence of various physics and chemicals on the growth and photosynthesis of Spirulina maxima. Ph.D. in Sciences applied, University of Paris, Paris, France. 